\title{
A Study on Compliment Response Strategies by Chinese College Students
}

\author{
Ying Cai \\ Foreign language Department, Dalian University of Technology, Dalian, China \\ Email: caiyingaaaa@163.com
}

\begin{abstract}
Complimenting behavior, as a common speech act of human beings, has become an intriguing topic in linguistics and its sub-branches. The study aims to collect and summarize the CR strategies by Chinese college students. An overall distribution is presented of CR strategies, choices of CR strategies by genders and choices of CR strategies under different contextual factors like relative social power or social distance between the speaker and the hearer. The findings show that CR strategies by Chinese college students have changed a lot and are much different with the traditional patterns: (1) Chinese college students prefer Acceptance strategy to Rejection strategy, and Implicit Acceptance strategy is the first choice. (2)The females have greater tendency to use Explicit Acceptance strategy than the males; whereas the males prefer to use Deflection and Rejection strategies. (3) People prefer to use the Explicit Acceptance strategy when they respond to the compliment from an unfamiliar person or a person with relative greater social power; whereas, Deflection and Rejection strategies are more frequently adopted when people respond to the compliment from a familiar person or a person without relatively greater social power. Under the guidance of pragmatic and sociolinguistics, CR strategies are discussed in terms of Politeness Theories and Social Distance and Social Power affect. It is concluded that the western cultural influences Chinese college students' employment of pragmatic strategies, which are mostly a compromise under the guidance by universal Politeness theories and Chinese socio-cultural context.
\end{abstract}

Index Terms - complimenting responses (CR) strategy, social distance (between speaker and hearer), relative social power (of speaker over hearer), politeness theories

\section{INTRODUCTION}

Complimenting behavior is a universal linguistic phenomenon. As a speech act which happens with a high frequency in our daily life, it plays a significant communicative function and serves to establish, consolidate and promote the interpersonal relationships. (Holmes, 1988) A proper complimenting behavior can make people closer and more harmonious. Being an adjacency pair, a compliment and a compliment response coexist. The responses to the compliment vary due to the social and individual elements. Different cultural customs, communicative topics, social power and gender etc. will affect compliment responses.

To explore Chinese compliment responses used by Chinese college students, the study discuss the distribution of Chinese compliment responses under the guidance of the related theories. The study intends to answer the following basic questions:

(1) What is the overall distribution of compliment response among Chinese college students?

(2) Will gender differences, social distance between the speaker and hearer, and the relative social power of the hearer over the speaker, do affect their response strategies?

(3) Can compliment response among Chinese college students be applied to politeness principles which are proposed by Leech, and Brown and Levinson?

\section{LITERATURE REVIEW}

\section{A. Studies on Compliment Responses}

The study of complimenting behavior has been one of the most intriguing topics in linguistics. There have been a lot of studies by many researchers such as Herbert, Holmes, Wolfson, etc. Their studies fell into the fields of pragmatics, discourse analysis, sociolinguistics, psycholinguistic and so on.

1. Pragmatics studies

Pomerantz is the first person who study compliment response strategies. According to Pomerantz, the speakers face a dilemma because they have to balance two contradictory conditions: to agree with one's compliment and to avoid self-praise. (Chen, Yang, 2010) While trying to meet one condition, the speaker will inevitably conflict with the other. Since the compliment response always contains a positive evaluation, how can one agree with the compliment without avoiding self-praise at the same time? It is therefore the addressee's task to solve the dilemma with the appropriate social manner.

Holmes studied complimenting behavior systematically. Her studies concentrate on compliment responses in 
different varieties of English and other languages. She analyzed the syntactic and lexical patterns of compliments and the functional categories of compliment responses in New Zealand English, based on a corpus of over 500 compliment data. Her data indicate that the most frequent response to a compliment in New Zealand was Accept. (Holmes, J.1986) She also studied complimenting behavior in terms of Brown and Levinson's Politeness Theory. She claimed that complimenting behavior is, positively affective speech acts on the one hand, and on the other, potentially face-threatening acts. (Wang, Tsai, 2004)

2. Socio-linguistic studies

Sociolinguistics endeavors to study the relationship between language and society, especially the social variability of language. It explains why people speak differently along with the differences in age, gender, and ethnicity and so on. The study of language and gender is one major interest in sociolinguistics. Compliment responses have also been discussed on the perspective of gender differences, such as "Paying compliments: A sex-preferential politeness strategy" by Janet Holmes. Holmes examined women's and men's complimenting behavior, and categorizes the compliment responses according to their function as well as the responder's sex. She further found that males ignored or evaded a compliment more often than women did. The results of her study reveal the existence of sex-preferential strategies for compliment responses. (Holmes, 1988)

3. Contrastive studies

Complimenting behavior has also been studied from the perspective of different language communities. Herbert has studied American and South African compliment responses spoken. He found out that in American English, two thirds of the time respondents to compliments do something other than to accept them. His data suggested that Americans exhibit a high frequency of compliment-expression but a low frequency of compliment-acceptance; South Africans exhibit a low frequency of compliment-expression but a high frequency of compliment-acceptance. He explained the contrast in terms of ideological differences between Americans and South Africans. That is, the high frequency of compliments and the low rate of acceptance in the U.S. data reflect American notions of equality and democratic idealism, whereas the low frequency of compliments and the high rate of acceptance are tied to elitism in South Africa. (Farghal, Al-Khatibb.2001)

In a word, much work has been done on the study of CR strategies, but the majority of the work was the research in English language. There is still a lack of researches in Chinese context. Based on the previous findings, the hypothesis of this research is that Chinese college students have different CR patterns. Gender and social factors do affect the adoption of the CR strategies. The hypothesis can boil down to the following points:

(1) Chinese college students nowadays prefer to accept compliments, not reject them.

(2) The females have greater tendency to accept compliments than the males.

(3) Participants relationship like social distance between the speaker and hearer and relative social power affects the CR strategy.

(4) Compliment response strategies among Chinese college students can be applied to politeness principles which are proposed by Leech, and Brown and Levinson

\section{B. Methodology}

1. Discourse completion task questionnaire

The data for this study was collected through the discourse completion task (DCT) questionnaire. The research method is chosen for the following reasons: First, DCT can be under control over the variables such as gender, social distance, social status. Second, it is convenient to collect and analyze the data. Third, DCT questionnaire serves to gain insights into social and pragmatic factors.

After careful collection and selection, the DCT questionnaire is made. The following is the summary of DCT questionnaire.

TABLE I

SUMMARY OF THE DCT QUESTIONNAIRE.

\begin{tabular}{lcc}
\hline Topic & Distance of the speaker and hearer & social status( the compliment-giver) \\
\hline Appearance & distant & equal \\
Appearance & close & high \\
Performance & distant & high \\
Performance & distant & low \\
Ability & close & low \\
Ability & close & equal \\
\hline
\end{tabular}

\section{Data processing}

Based mainly on the previous research by Herbert and Holmes, this paper analyzed six main strategies of CR: Explicit Acceptance, Implicit acceptance, Deflection, Rejection, No verbal acknowledgment, Combination. The college students that have been researched are from various majors in Dalian University of Technology, with a total number of 123, 58 males and 65 females. The data collected 738 responses altogether.

After collection, the responses were put into the sub-categories. Then the sub-categories of CR were coded, the main strategies were calculated for each group. In the present study, the data were mainly analyzed in terms of the six main strategies by gender, participant's relationships (social distance, social status). 


\section{RESULTS}

\section{A. Distributions of CR Strategies}

In this section, results of the DCT data are presented. Responses are categorized into CR strategies, which are consistent with the complimenting categories presented by Herbert, Holmes and Shi Gengshan. The frequencies of the main strategies are analyzed in terms of Chinese college students as a whole and in different gender groups.

Categories of CR strategies

Under the guidance of Holmes and Herbert's taxonomy of compliment responses, some improvement is made to satisfy Chinese context. Table II shows a new coding scheme of Chinese CR strategies.

TABLE II

SUMMARY OF THE DCT QUESTIONNAIRE

\begin{tabular}{lll}
\hline Main strategy & Sub-strategy & Example \\
\hline Explicit Acceptance & Appreciation token & 谢谢! \\
& Comment acceptance & 谢谢, 我也挺喜欢的. \\
& Praise upgrade & 那当然, 厉害吧! \\
& Association & 谢谢, 最近刚剪的。 \\
Implicit acceptance & Scale down & 还行吧! \\
& Return & 你的想法也不错 \\
& Association & 努力就会有成绩 \\
& Comment history & \\
Reflection & Reassignment & 我准备了好久 \\
& Confirmation & 是爸妈基因好 \\
& Disagreement & 真的? \\
& Qualification & 我不厉害 \\
& No verbal acknowledgment & 很多同学都比我厉害的 \\
& Combination & 笑 \\
& & 是吗? 谢谢啊, 我刚剪的,
\end{tabular}

The data collected consists of 123 responses altogether (58 males and 65 females). After the sub-strategies were coded, the main strategies were calculated for each group. Moreover, the data were also analyzed in terms of the five strategies by gender, social distance and relative social status.

2. The overall distributions of CR strategies

As to the overall distribution of CR strategies, Table III indicates the breakdown of the responses in terms of the main strategies.

TABLE III

THE OVERALL DISTRIBUTION OF CR STRATEGIES

\begin{tabular}{lcc}
\hline CR Strategies & \%Raw & Rank Order \\
\hline Implicit acceptance & $37.0(273)$ & 1 \\
Explicit Acceptance & $35.3(261)$ & 2 \\
Deflection & $10.3(76)$ & 3 \\
No verbal acknowledgment & $8.1(60)$ & 4 \\
Rejection & $3.4(25)$ & 5 \\
Combination & $2.2(16)$ & 6 \\
\hline Total & $100(738)$ & \\
\hline
\end{tabular}

The table shows that the "acceptance" strategies, explicit and implicit, amount to $72.3 \%$ of all the CRs, which are much more frequent than "Deflection" type strategies (10\%), "No verbal acknowledgment" strategy (8.1\%) and "Rejection" strategy (3.4\%). The rest belong to Combination of the different strategies above, accounting for $2.2 \%$ of the total occurrences of the CRs.

B. Distributions of CR Strategies by Gender

Table 3.2 presents the overall distribution of CR strategies of the two gender group. 
TABLE IV

THE OVERALL DISTRIBUTION OF CR STRATEGIES BY GENDER.

\begin{tabular}{lcccc}
\hline CR strategies & Male & & Female & \\
& $\%($ Raw $)$ & Rank Order & $\%($ Raw $)$ & Rank Order \\
\hline Implicit acceptance & $37.4(130)$ & 1 & $36.7(143)$ & 2 \\
Explicit Acceptance & $31.9(111)$ & 2 & $38.5(150)$ & 1 \\
Deflection & $10.9(38)$ & 3 & $9.7(38)$ & 3 \\
No verbal acknowledgment & $7.8(27)$ & 4 & $7.2(28)$ & 4 \\
Rejection & $4.3(15)$ & 5 & $3.8(15)$ & 5 \\
Combination & $2.6(9)$ & 6 & $1.8(7)$ & 6 \\
\hline Total & $100(348)$ & & $100(390)$ & \\
\hline
\end{tabular}

As the table suggests, we can find out that: first, females shows a much stronger preference to Explicit Acceptance $(38.5 \%)$ than male. "Explicit Acceptance" even surpasses "Implicit acceptance (36.7\%)" and ranks the first place. In other CR strategies, male has a greater tendency to use Implicit Acceptance, Deflection, No verbal acknowledgment, Rejection and Combination strategies.

\section{Distributions of CR Strategies by Social Distance}

The discourse completion tasks in the questionnaire are classified into different groups according to the social distance between speaker and hearer: close and distant relationship. The distribution of CR strategies is presented below.

TABLE V

THE DISTRIBUTION OF CR STRATEGIES BY SOCIAL DISTANCE.

\begin{tabular}{lcccc}
\hline CR strategies & $\begin{array}{c}\text { Distant } \\
\%(\text { Raw })\end{array}$ & Rank Order & $\begin{array}{c}\text { Close } \\
\%(\text { Raw })\end{array}$ & Rank Order \\
\hline Implicit acceptance & $33.9(125)$ & 2 & $40.1(148)$ & 1 \\
Explicit Acceptance & $44.4(164)$ & 1 & $26.3(97)$ & 2 \\
Deflection & $8.7(32)$ & 3 & $11.9(44)$ & 4 \\
No verbal acknowledgment & $3.0(11)$ & 5 & $13.3(49)$ & 3 \\
Rejection & $3.0(11)$ & 5 & $3.8(14)$ & 5 \\
Combination & $4.1(15)$ & 4 & $0.03(1)$ & 6 \\
\hline Total & $100(369)$ & & $100(369)$ & \\
\hline
\end{tabular}

The table suggest that: first, CR strategies are affected by the social distance between speaker and hearer; second, people prefer the "Explicit Acceptance" strategies (44.4\%) most when their relationship is distant, whereas "Implicit acceptance" strategies (40.1\%) most when they are close to each other; third, people have greater tendency to adopt "Deflection", "No verbal acknowledgment", and "Rejection" strategies when their relationships are close; forth, "Combination" surpasses "No verbal acknowledgment and "Rejection" strategies when people respond to an unfamiliar compliment-giver; fifth, "No verbal acknowledgment" surpasses "Deflection" strategy in the interaction with a familiar person.

\section{Distributions of CR Strategies by Relative Social Status.}

The DCT tasks in the questionnaire are classified into different groups according to the relative social status. "Equal" means the speaker and hearer are of the equal status. "Up-down" means the compliment-giver's status is higher than the compliment-receiver, such as teacher-student. "Down-up" is contrary to "Up-down", with the compliment-giver's status lower than the compliment-receiver, such as senior-junior. Table VI presents the distribution of CR strategies by Relative Social Status.

TABLE VI

THE DISTRIBUTION OF CR STRATEGIES BY RELATIVE SOCIAL STATUS

\begin{tabular}{|c|c|c|c|c|c|c|}
\hline \multirow[t]{2}{*}{ CR strategies } & \multicolumn{2}{|l|}{ Equal } & \multicolumn{2}{|l|}{ Up-down } & \multicolumn{2}{|l|}{ Down-up } \\
\hline & $\%$ ( Raw) & Rank Order & $\%$ (Raw) & Rank Order & $\%$ ( Raw) & Rank Order \\
\hline Implicit Acceptance & $45.1(111)$ & 1 & $14.6(36)$ & 2 & $51.2(126)$ & 1 \\
\hline Explicit Acceptance & $32.5(80)$ & 2 & $51.6(127)$ & 1 & $22.0(54)$ & 2 \\
\hline Deflection & $10.2(25)$ & 3 & $7.3(18)$ & 4 & $13.4(33)$ & 3 \\
\hline No verbal acknowledgment & $2.4(6)$ & 5 & $16.7(41)$ & 3 & $5.3(13)$ & 4 \\
\hline Rejection & $3.3(8)$ & 4 & $3.3(8)$ & 6 & $3.7(9)$ & 5 \\
\hline \multirow[t]{2}{*}{ Combination } & $2.0(5)$ & 6 & $3.7(9)$ & 5 & $0.8(2)$ & 6 \\
\hline & \multicolumn{2}{|c|}{$100(246)$} & \multicolumn{2}{|c|}{$100(246)$} & $100(246)$ & \\
\hline
\end{tabular}

The table suggests that: First, "Explicit Acceptance" strategy(51.6\%) is preferred most when the participants' relative social status is Up-down, whereas "Implicit Acceptance" strategy is preferred most when the participants' relative social status is "Equal" and "Down-up"; second, "No verbal acknowledgment" ranked before "Deflection" strategy in "Up-down" situation; third, "Rejection" (3.3\%) surpasses "No verbal acknowledgment" strategy (2.4\%) and ranks forth in "Equal" situation; forth, "Combination" rises from the bottom and ranks before "Rejection" strategy in "Up-down" situation

In summary, Chinese college students adopted various strategies when they respond to compliment. Generally 
speaking, they prefer "Acceptance" strategy, implicit or explicit. Moreover, two genders prefer different CR strategies, and contextual factors do affect the choice of CR strategies. In the next part, these results will be discussed in detail.

\section{DISCUSSION}

The four research questions will be discussed on the basis of results under the guidance of the politeness theories.

\section{A. The Overall Distribution of CR Strategies}

The results show that Chinese college students prefer to take a positive CR behavior. First, Acceptance strategy, implicit and explicit, is found to be adopted more frequently than other strategies. Chinese people used to be reluctant to accept a compliment directly under traditional Chinese customs. Meanwhile, influenced by the western culture, people now are more likely to accept a compliment instead of the traditional rejection responses. As to Leech's Politeness Principle, the Maxim of Compliance requires people to minimize our disagreement with others while maximize agreement with others. The Explicit Acceptance Strategies is in consistent with the Maxim. The frequent responses are

"Thank you!" which shows the agreement with the speaker's appreciation.

Second, "No verbal acknowledgment" strategy, with higher frequency than Rejection, rates the forth in this study. Non-verbal responses mostly are some expression like "smile", which rarely happens in the western languages. Herbert put it into the category of "Rejection", because complimenting behavior is an adjacency pair in western communications, that is, a compliment and a compliment response must coexist. (Herbert,1990) No compliment response is a flout to the Cooperative Principles proposed by Grice, and means a rejection to compliment in western culture. However, in Chinese culture, complimenting behavior is not necessary to be an adjacency pair. "That people just smile" without verbal acknowledge mostly means a silent acceptance or showing politeness.

Third, Chinese college students tend to respond to compliment in an implicit way. The Maxim of Modesty is especially true in China. People are reluctant to exaggerate their achievement or show off. When responding to a compliment, people still prefer to take an implicit way. Although they are influenced by western cultures and less frequently adopt a Rejection Strategy, they still avoid self-praise.

Implicit Acceptance, Deflection and No verbal acknowledgement form the so called "Self-praise avoidance" devices proposed by Pomerantz. Those are the three strategies people adopt as Face Saving strategies to balance the Face Threatening Act. According to my research, these strategies are frequently used by Chinese college students. It is safe to say that Chinese college students are more capable of solving the face threatening behavior, by responding in different mild way instead of openly acceptance or direct rejection.

Forth, people sometimes respond to a compliment by adopting two or more strategies as a combination. For example, “谢谢老师夸奖, 我还有许多有待提高。”(Thanks for the praise. I still need to improve myself)(Explicit acceptance+ scale down），“谢谢啊，我刚剪的，你的发型也蛮好的。” (“Thanks, I did it just now. Your hairstyle looks good too) (Explicit acceptance+ informative comment+ return). In this circumstance, the addressee does not simply adopt a single strategy of Acceptance, Deflection or Rejection. Their responses strategically solve the CR dilemma proposed by Pomerantz. They agree with the compliment and avoid self-praise at the same time. Politeness and modesty are properly shown.

\section{B. CR Strategies by Gender}

The second research question is to reveal the relation between social variable of gender and CR strategies. The result in Table IV are concluded as follows:

First, Female shows a much stronger preference to "Explicit Acceptance" (38.5\%) than male. "Explicit Acceptance" even surpasses "Implicit acceptance (36.7\%)" and ranks the first place.

Second, male tends to employ "Implicit Acceptance", "Deflection", "No verbal acknowledgment" and "Rejection strategies" more often than female.

These findings are consistent with Quan and Ye's studies. Both studies reveal that females tend to accept compliments, while males tend to opt out. (Shi, 2008)

However, some studies, both from home and abroad, investigate CR strategies and gender in a more detailed way. The gender of the speaker and hearer are clarified in these analyses. Holmes has found out that compliments offered by males are more likely to be accepted than compliments offered by females. Therefore, this paper only shows a pilot study on CR strategies and gender. The more elaborate researches need to be further carried out.

\section{CR Strategies and Participants Relationship (Social Distance and Relative Social Status)}

This paper also aims to investigate the relationship between the interaction participants and CR strategies. That is, do people's responses to compliments vary according to the social distance between speaker and hearer, and their relative social status? If so, how do they differ?

Results suggest the variables of participants' relationship exert a strong effect on respondents' CR strategies. "Explicit Acceptance" strategy is preferred when the compliment-giver's social status is relative high or is an unfamiliar; whereas, "Deflection" and "Rejection" strategies are more frequently adopted when compliment-giver's social status isn't relatively privileged or is a familiar. 
There is no doubt that people don't talk in the same manner on all occasions. Therefore, in conversation analysis, the factors need to be considered which contribute to the changes of ways of speaking. It is assumed by linguistics that styles of utterances are influenced by variables like social status, age, gender, culture, etc. When talking to people who have power over us or are strangers, we speak in a more polite way. When talking to people who are close to us or without relative high status over us, we will speak more freely without afraid of threatening one's face. It is best analyzed by Brown and Levinson. Politeness is context-dependent. Contexts such as social distance between the speaker and the hearer, the relative power of the hearer over the speaker (their age, sex, and status), the rank of imposition, can all affect politeness degree and strategy choices. According to Brown and Levinson's formula, Face Threatening Acts as W(x) (Yang, 2008)

$\mathrm{W}(\mathrm{x})=$ Distance (between the speaker and the hearer) + Power (of the hearer over the speaker) + Rank(x)

The more distant between the speaker and hearer, the more power of the hearer over the speaker, the greater imposition of the speech act, the speech act is more face-threatening. Therefore, the speaker should choose a more face-saving strategy.

As to Brown and Levinson's politeness theory, speech act like complimenting is hearer beneficial. It reflects the strong positive politeness orientation. As the positive politeness strategies are concerned with the person's positive face, the addressee may risk threatening the addresser's positive face by rejecting the compliment, because he implies that the compliment proposition is not true. When rejecting a compliment, the compliment-receiver does not attach great importance to maintaining the compliment-giver's face or leaving a bad impression. They may have a particular concern to perform the Face Threatening Act (FTA), such as avoiding self-praise, rather than satisfying the compliment-giver's face needs. In order not to cause a FTA, the compliment-receiver may then be forced to accept a compliment, and even show his or her gratitude for it.

In summary, complimenting behavior is the speech act that shows the practical use of Politeness Theories. Compliment response strategies will vary due to different customs. The key point is what is considered polite in a specific culture and whose face is more important in social interaction. As for Chinese culture, according to my study, it is the face of the addressee that is the major concern of communicative interaction. When responding to a compliment, the compliment-receiver will avoid threatening the face of the compliment-giver's face by adopting the strategies of "Implicit acceptance", "Deflection" and "No verbal acknowledgment".

\section{CONClusion}

This study investigates the Complimenting Response patterns used by Chinese college students in terms of Pragmatic and Sociolinguistics. It is discussed how CR is guided by the Politeness Theories and how social variables like gender and contextual factors like Social distance and Social Power affect the choices of CR strategies

It is concluded that CR strategies by Chinese college students are mostly a compromise under the guidance by universal Politeness theories and Chinese socio-cultural context. Furthermore, this paper presents a real picture of CR strategies by Chinese college students against the long-rooted traditional Chinese CR patterns. The study benefits the cross-cultural communication studies of speech act, as it reminds us to take a dynamic view in investigating the communication among different cultures.

\section{APPEndix I The DCT QuestionnAIRE}

\section{汉语称赞语运用调查问卷}

尊敬的调查协助者:

您好! 非常感谢您在百忙之中给予本调查以大力协助。这次问卷是专门为调查汉语称赞语而设计的, 您的回 答具有重大意义。请您结合下列情景, 将您最可能说的话写下来。谢谢您宝贵的时间和精力。本调查只用作数 据统计, 绝对不会对外泄露您的个人信息, 请如实回答。

您的性别:

专业:

您的教育经历: 硕士生 (研一, 研二, 研三)

本科生（大一，大二，大三，大四）

外语学习经历: 语种学习年限程度 语种学习年限程度

1.你刚换了一个新发型, 路上遇到了不太熟的同学, 她对你说：“呀, 你这个新发型真不错! ”

你的回答:

2.你帮朋友修了电脑，他/她对你说：“你太厉害了!”

你的回答:

3. 过年的时候, 从小看你长大的长辈对你说: “呦, 咱闺女越长越漂亮了! /这小伙越长越帅了。”

你的回答: 
4. 你参加了歌唱比赛, 比赛过后, 你不太熟悉的老师对你说: “你表现得不错, 声音和选的歌曲都挺好! ” 你的回答:

5. 你是学生会文化部长, 策划迎新晚会时, 经常协助你工作的干事对你说: “部长, 我觉得你这个想法特别 好, 特有新意。”

你的回答:

6. 你在英语六级考试中拿了学校最高分, 你不太熟悉的学妹对你说: “学姐/学长, 听说你六级考了 600 分, 太厉害了!”

你的回答:

非常感谢您的帮助!

\section{REFERENCES}

[1] Andrea Golato. (2002). German Compliment Responses. Journal of Pragmatics, 34: 547-571.

[2] Chen, Rong. (2010). Responding to Compliments in Chinese: Has it changed?. Journal of Pragmatics, 42: 1951-1963.

[3] Herbert, R. (1990).Sex-based Differences in Compliment Behavior. Language in society, 19: 201-224.

[4] Holmes, J. (1988). Paying Compliments: A Sex-preferential Positive Politeness Strategy. Journal of Pragmatics, 12: 445-465.

[5] Holmes, J. (1986). Compliments and Compliment Responses in New Zealand English. Anthropological Linguistics, 28: 485-508.

[6] $\mathrm{Hu}$, Xiaoli. (2002). A Contrastive Study of Compliments in English and in Chinese-- In Response of Culture-and-Language Relationship. Beijing: Beijing Language and Culture University.

[7] Ji, Shaojun. (2000). 'Face' and Polite Verbal Behaviors in Chinese Culture. Journal of Pragmatics, 32: 1059-1962.

[8] Miriam R. Eisentein. (1989). The Dynamic Interlanguage: Empirical Studies in Second Language Variation. New York: New York University.

[9] Mohammed Farghal, Mahmoud A. Al-Khatibb. (2001). Jordanian college students' responses to compliments: A pilot study.. Journal of Pragmatics, 33: 1485-1502.

[10] Nai, Yunguo. (2004). Social Variation in Compliment Response Strategies. Chengdu: Southeast Jiaotong University.

[11] N. Lorenzo-Dus. (2001). Compliment Responses among British and Spanish University Students: A Contrastive study. Journal of Pragmatics, 33: 107-127.

[12] Quan, Lihong. (2004). Gender Differences in Applying Compliments and Compliment Responses in Chinese Context. CELEA Journal, 27: 63-66.

[13] Shi, Gengshan. (2008). Approaching Gender in Chinese Compliments. Beijing: Science Press.

[14] Tang, ChenHsin, Zhang Grace Qiao. (2009). A contrastive Study of Compliment Responses Among Australian. Journal of Pragmatics, 41: 325-345.

[15] Wang, Yufang, Tsai, Pihua. (2004). An Empirical Study on Compliments and Compliment Responses in Taiwan Mandarin Conversation. Taiwan: Providence University, National Chengchi University.

[16] Wei, Chunli. (2006). A Contrastive Study of English and Chinese Compliments. Guangxi University.

[17] Yang, Chaoguang. (2008). Language Use in Context--A Course in Pragmatics. Beijing: University of International Business and Economics Press.

[18] Yi, Yuan. (2002). Compliments And Compliment Responses in Kunming Chinese. International Pragmatics Association, $12: 2$. $183-226$.

[19] Zhang, Yongmei. (2002).A Contrastive Study on Compliments and Compliment Responses in Chinese and American English. Henan: Henan University.

[20] Gui, ShiChun, Wang, Chuming. (2004). Contemporary Pragmatics. Beijing: Foreign Language Teaching and Research Press.

[21] Xu, Lisheng. (2006). Studying Language and Its Use: An Intercultural Approach, Shanghai: Shanghai foreign language education press.

Ying Cai was born in Shenyang, China in 1987. She received her B.A. degree in English from Dalian University of Technology, China in 2006.

She is currently pursuing her M.A. in Linguistics in Dalian University of Technology, Dalian, China. Her research interests include cognitive linguistics and Pragmatics. 